University of Nebraska - Lincoln

DigitalCommons@University of Nebraska - Lincoln

$1-22-2001$

\title{
Potential phase control of chromium oxide thin films prepared by laser-initiated organometallic chemical vapor deposition
}

\author{
Ruihua Cheng \\ University of Nebraska-Lincoln \\ C.N. Borca \\ University of Nebraska-Lincoln \\ Peter A. Dowben \\ University of Nebraska-Lincoln, pdowben@unl.edu \\ Shane Stadler \\ Naval Research Laboratory, Materials Physics Branch, Washington, D.C., stadler@phys.Isu.edu \\ Y.U. Idzerda \\ Naval Research Laboratory, Materials Physics Branch, Washington, D.C.
}

Follow this and additional works at: https://digitalcommons.unl.edu/physicsdowben

Part of the Physics Commons

Cheng, Ruihua; Borca, C.N.; Dowben, Peter A.; Stadler, Shane; and Idzerda, Y.U., "Potential phase control of chromium oxide thin films prepared by laser-initiated organometallic chemical vapor deposition" (2001). Peter Dowben Publications. 26.

https://digitalcommons.unl.edu/physicsdowben/26

This Article is brought to you for free and open access by the Research Papers in Physics and Astronomy at DigitalCommons@University of Nebraska - Lincoln. It has been accepted for inclusion in Peter Dowben Publications by an authorized administrator of DigitalCommons@University of Nebraska - Lincoln. 


\title{
Potential phase control of chromium oxide thin films prepared by laser-initiated organometallic chemical vapor deposition
}

\author{
Ruihua Cheng, C. N. Borca, and P. A. Dowben ${ }^{\mathrm{a})}$ \\ Department of Physics and Astronomy and the Center for Materials Research and Analysis (CMRA), \\ Behlen Laboratory of Physics, University of Nebraska-Lincoln, Lincoln, Nebraska 68588-0111 \\ Shane Stadler and Y. U. Idzerda \\ Naval Research Laboratory, Materials Physics Branch, Washington, D.C. 20375
}

(Received 31 July 2000; accepted for publication 28 November 2000)

\begin{abstract}
We have used laser-initiated chemical vapor deposition to grow the chromium oxide thin films through the oxidation of $\mathrm{Cr}(\mathrm{CO})_{6}$ in an oxygen environment. While both $\mathrm{Cr}_{2} \mathrm{O}_{3}$ and $\mathrm{CrO}_{2}$ are present in the film, the relative weight of each phase depends on the oxygen partial pressure. The Curie temperature of the film increases and approaches the bulk $T_{C}$ of $\mathrm{CrO}_{2}(397 \mathrm{~K})$ as the partial oxygen pressure is increased. (C) 2001 American Institute of Physics. [DOI: 10.1063/1.1343846]
\end{abstract}

The high electron polarization, in addition to the halfmetallic character of the surface ${ }^{1}$ makes $\mathrm{CrO}_{2}$ an attractive material for spin-tunnel junctions ${ }^{2}$ (where very large tunneling magnetoresistance is expected), as well as other magnetoresistive devices. ${ }^{3,4}$ The insulating antiferromagnetic chromium oxide $\mathrm{Cr}_{2} \mathrm{O}_{3}$ has a Néel temperature $307 \mathrm{~K}$ and is suitable for tunnel junction barriers ${ }^{4}$ both below and above the Néel temperature. The ferromagnetic chromium oxide $\mathrm{CrO}_{2}$ with $T_{c} 397 \mathrm{~K}$ (Ref. 5) has been predicted to be half metallic (metallic for one spin direction while insulating for the other spin direction) by band structure calculations, ${ }^{1,6-9}$ though Kulatov and Mazin found $\mathrm{CrO}_{2}$ to be insulating in both spin directions. ${ }^{10}$ Evidence of $80 \%$ to $100 \%$ polarization, consistent with the half-metallic character of $\mathrm{CrO}_{2}$, were observed in spin-polarized photoemission, ${ }^{11}$ vacuum tunneling, ${ }^{12}$ and Andreev scattering. ${ }^{13,14}$ Biquadratic coupling and/or giant magnetoresistance, observed above the Néel temperature for $\mathrm{Fe} / \mathrm{Cr}$ multilayers, ${ }^{15,16}$ may be enhanced in $\mathrm{CrO}_{2} / \mathrm{Cr}_{2} \mathrm{O}_{3}$ multilayers because of the lower Néel temperature and insulating character of $\mathrm{Cr}_{2} \mathrm{O}_{3}$. Below the Néel temperature, unidirectional magnetic anisotropy and exchange bias at the interface between the ferromagnetic and antiferromagnet layers may be expected, as in the case of $\mathrm{NiFe} / \mathrm{NiO},{ }^{17,18} \mathrm{NiFe} / \mathrm{FeMn},{ }^{19}$ and $\mathrm{Fe} / \mathrm{Cr}$ (Ref. 20) bilayer and multilayer systems.

It is difficult to fabricate $\mathrm{CrO}_{2}$ ultrathin films using conventional methods because $\mathrm{CrO}_{2}$ is metastable. This is not altogether bad, as the two phases $\mathrm{CrO}_{2} / \mathrm{Cr}_{2} \mathrm{O}_{3}$ system exhibits higher magnetoresistance than the pure material. ${ }^{4}$ The oxidation of the organometallic complex hexacarbonyl $\mathrm{Cr}(\mathrm{CO})_{6}$ has the potential for selective deposition of $\mathrm{CrO}_{2} \cdot{ }^{21-23}$ These studies have established that chromium oxides are the thermodynamic sink of chromium hexacarbonyl decomposition $^{23}$ and the oxidation is further aided by the presence of an ambient oxygen background. ${ }^{21,22}$ By modifying this organometallic chemical vapor deposition procedure, we have been able to fabricate the ferromagnetic and antiferromagnetic chromium oxides. Here, we describe both the growth and the magnetic properties of these films.

\footnotetext{
a) Author to whom correspondence should be addressed; electronic mail: pdowben@unl.edu
}

The growth of the chromium oxide films were carried out on $\mathrm{Si}(111)$ substrates in an ultrahigh vacuum chamber, maintained at a base pressure at $1.0^{-9}$ Torr or less. This chamber was designed for laser initiated chemical vapor deposition as described elsewhere. ${ }^{24,25}$ The photolytic decomposition and oxidation of $\mathrm{Cr}(\mathrm{CO})_{6}$ was performed by a commercial nitrogen laser with the main emission line at 337 $\mathrm{nm}$ (corresponding to $3.69 \mathrm{eV}$ ). The ambient oxygen $\left(\mathrm{O}_{2}\right)$ atmosphere was varied from $1 \times 10^{-7}$ to $1 \times 10^{-5}$ Torr relative to the $\mathrm{Cr}(\mathrm{CO})_{6}$ partial pressure of $1 \times 10^{-5}$ Torr, uncorrected for ionization gauge cross section and monitored with a quadruple mass spectrometer operated in pulse counting mode.

The x-ray adsorption spectroscopy (XAS) and magnetic circular dichroism (MCD) spectra were taken at the U4B beam line at the National Synchrotron Light Source at Brookhaven National Laboratory. The photon beam was set $\sim 75 \%$ helicity and the incident beam was $45^{\circ}$ off from the surface normal. For magnetizing the sample, a 200 Oe pulsed field was applied in plane. The MCD spectra were recorded by alternating the magnetization at every photon energy with a fixed helicity of the incident light.

The nonmagnetic chromium oxide phase is dominated by $\mathrm{Cr}_{2} \mathrm{O}_{3}$ crystallites with a pronounced preferential orientation. Figure 1 shows the light polarization dependent $\mathrm{Cr} \mathrm{L}$ edge [Fig. 1(a)] and O K edge [Fig. 1(b)] XAS of the chromium oxide film fabricated with an ambient of 5 $\times 10^{-7}$ Torr oxygen partial pressure. At energies above the $\mathrm{Cr} \mathrm{L}_{3}$ edge, the spectra are dominated by two peaks, around $577.7 \mathrm{eV}$ and $579 \mathrm{eV}$, followed by another two peaks above the $\mathrm{L}_{2}$ edge, around $586.9 \mathrm{eV}$ and $588.5 \mathrm{eV}$. The oxygen spectra [Fig. 1(b)] are first dominated by a large feature between 532 and $535 \mathrm{eV}$. This oxygen XAS spectra is similar to the expected XAS spectra of $\mathrm{Cr}_{2} \mathrm{O}_{3}$ (Ref. 26) while the chromium L edge spectra are consistent with a mixed oxide. ${ }^{1}$ There is a strong dependence of the spectra on the light incidence angle, particularly at the oxygen edge. This originates from the orientation of $\mathrm{O}-2 p-\mathrm{Cr}-3 d$ hybrid states with respect to the crystalline axes. ${ }^{26}$

The polarization dependence of the XAS and the x-ray diffraction (XRD) results indicate texture growth in our films. The XRD pattern, shown as the inset in Fig. 1, indi- 


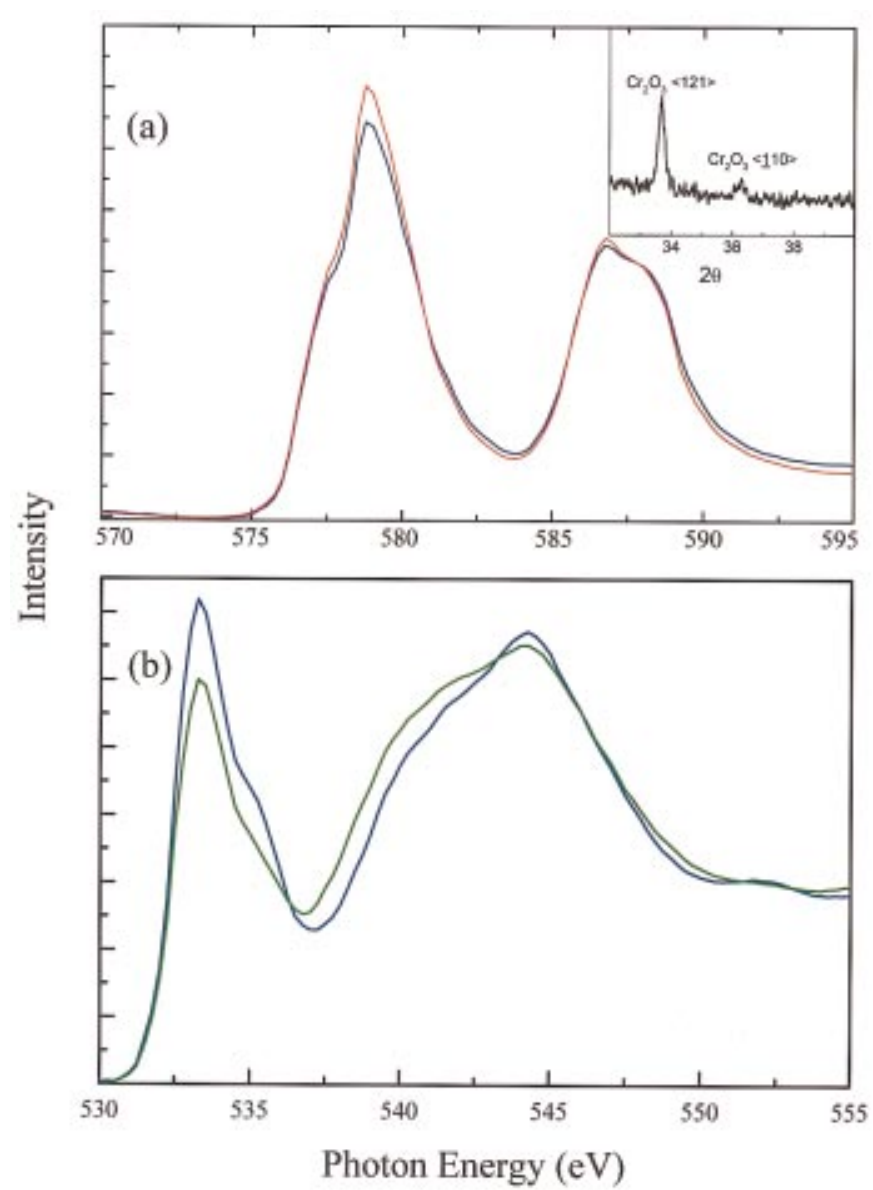

FIG. 1. (Color) XAS polarization dependence. The polarization dependent XAS for $\mathrm{Cr} \mathrm{L}$ edge of film fabricated in an ambient $\mathrm{O}_{2}\left(5 \times 10^{-7}\right.$ Torr $)$ background is shown in (a). The data shown as red line was taken at a $70^{\circ}$ incident angle, while the blue solid line shows the XAS data for normal incidence (pure s-polarized light). The polarization dependence of XAS at O $\mathrm{K}$ edge is shown in (b). The data shown as blue is for normal light incidence (pure $s$ polarized), and green is for a $55^{\circ}$ light incidence angle. The XRD data for the film fabricated with ambient $\mathrm{O}_{2}$ pressure $5 \times 10^{-6}$ Torr relative to the $\mathrm{Cr}(\mathrm{CO})_{6}$ partial pressure of $1 \times 10^{-5}$ Torr is shown as the inset.

cates that the $\mathrm{Cr}_{2} \mathrm{O}_{3}$ rich samples grown on $\mathrm{Si}(111)$ adopt a rhombohedral structure ( $\mathrm{R} \overline{3} C$ space group). Strong texture growth is characteristic of other chromium oxide thin films grown by chemical vapor deposition. ${ }^{2,14}$ As we increase the partial $\mathrm{O}_{2}$ pressure, the fraction of $\mathrm{Cr}_{2} \mathrm{O}_{3}$ decreases. We find no evidence of the $\mathrm{Cr}_{2} \mathrm{O}_{5}$ or $\mathrm{CrO}_{3}$ phases in XRD but do not exclude the possibility of a very small minority fraction. In the case of $\mathrm{CrO}_{2}$ rich samples, the structure identification in $\mathrm{XRD}$ is not conclusive due to the fact that both $\mathrm{Si}(111)$ and tetragonal $\mathrm{CrO}_{2}$ (110) diffraction peaks overlap.

The coexistence of $\mathrm{CrO}_{2}$ and $\mathrm{Cr}_{2} \mathrm{O}_{3}$ is evident in the hysteresis loop obtained at $100 \mathrm{~K}$, with the applied magnetic field in the plane of the film, shown in Fig. 2(a). The curve shown is for the sample fabricated with an $\mathrm{O}_{2}$ pressure of $2 \times 10^{-7}$ Torr relative to the $\mathrm{Cr}(\mathrm{CO})_{6}$ partial pressure of 1 $\times 10^{-5}$ Torr. The coercive force for left-hand side half loop is 250 Oe while for right-hand side half loop it is 150 Oe. The fact that the coercive field is often not symmetric in our films suggests uniaxial magnetic anisotropy, ${ }^{17-20}$ or exchange coupled bias $^{27,28}$ between the textured domains of antiferromagnetic $\mathrm{Cr}_{2} \mathrm{O}_{3}$ and $\mathrm{CrO}_{2}$. In addition, antiferromagnetic hysteresis is observed at higher fields [Fig. 2(a)]. Figure 2(b) is $\mathrm{Cr}$ L edge MCD signal of film fabricated with ambient $\mathrm{O}_{2} 5 \times 10^{-6}$ Torr. Note the evidence for magnetic order in the $\mathrm{CrO}_{2} t_{2 g}$ and $e_{g}$ bands for both $\mathrm{L}_{2}$ and $\mathrm{L}_{3}$ edges. ${ }^{29}$ The signal indicates the strong ferromagnetic character of $\mathrm{CrO}_{2},{ }^{26}$ though we attribute some $e_{g}$ like weight to small amount of $\mathrm{Cr}_{2} \mathrm{O}_{3}$, even for samples fabricated at these higher oxygen partial pressures.

Figure 3 shows the magnetization versus temperature obtained from superconducting quantum interference device magnetometry. The critical temperature clearly depends upon the oxygen partial pressure at the time of film fabrication. Samples fabricated at $2 \times 10^{-7}$ Torr oxygen partial pressure relative to the $\mathrm{Cr}(\mathrm{CO})_{6}$ partial pressure of 1 $\times 10^{-5}$ Torr exhibit the Curie temperature of $345 \pm 10 \mathrm{~K}$. Samples fabricated at the higher $1 \times 10^{-6}$ Torr oxygen partial pressure (relative to the $\mathrm{Cr}(\mathrm{CO})_{6}$ partial pressure of 1 $\times 10^{-5}$ Torr) exhibit the higher Curie temperature of about $390 \pm 10 \mathrm{~K}$. The absence of a sharp $T_{c}$ and the presence of a long tail in the magnetization curves (Fig. 3), near the critical temperature, are again suggestive of a two phase system. When we increase the $\mathrm{O}_{2}$ partial pressure, the amount of $\mathrm{CrO}_{2}$ phase increases and the critical temperature approaches the expected $T_{c}$ of $\mathrm{CrO}_{2}{ }^{4}$ The samples characterized by Au-

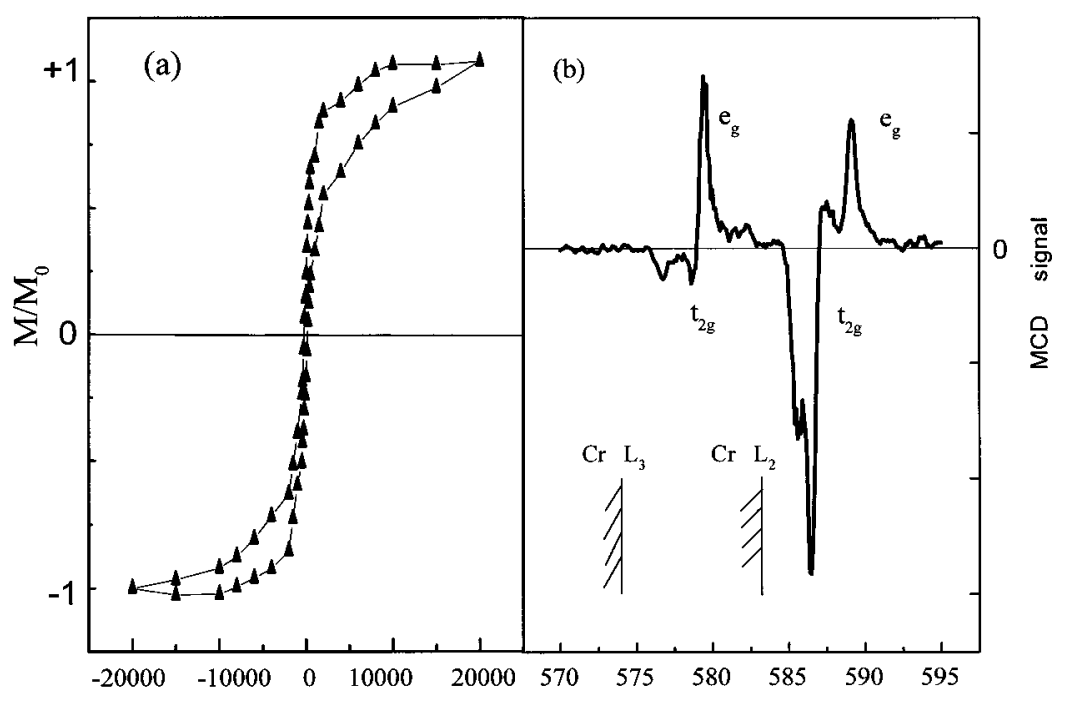

Field (Oe)

Photon Energy (eV)

Downloaded 06 Sep 2006 to 129.93.16.206. Redistribution subject to AIP license or copyright, see http://apl.aip.org/apl/copyright.jsp
FIG. 2. (a) Hysteresis loop was taken at $100 \mathrm{~K}$ of the film with ambient $\mathrm{O}_{2}$ pressure $2 \times 10^{-7}$ Torr. (b) The $\mathrm{CrL}_{2,3}$ edge MCD signal was taken at room temperature of the film fabricated with ambient $\mathrm{O}_{2}$ pressure 5 $\times 10^{-6}$ Torr relative to the $\mathrm{Cr}(\mathrm{CO})_{6}$ partial pressure of $1 \times 10^{-5}$ Torr. 


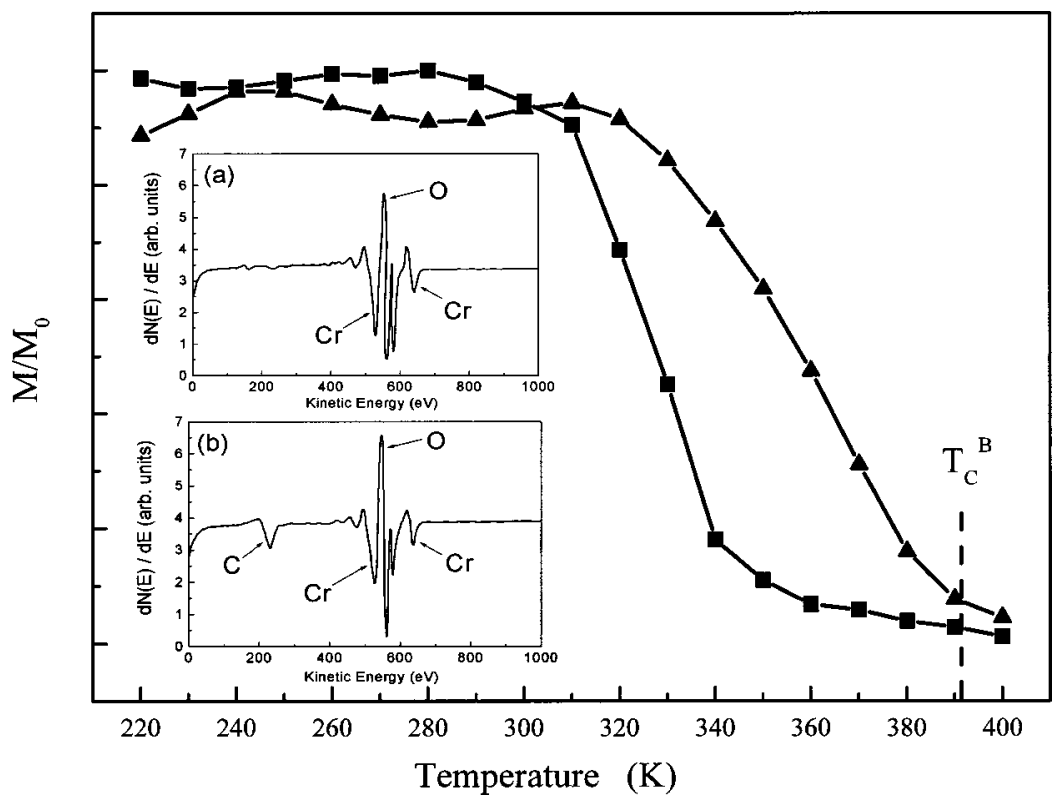

FIG. 3. The magnetization $(M)$ vs temperature $(T)$ at an applied field of $H=500$ Oe. Data are shown for two films: the data $(\boldsymbol{\square})$ were taken from the film fabricated in an $\mathrm{O}_{2}$ pressure of $2 \times 10^{-7}$ Torr relative to the $\mathrm{Cr}(\mathrm{CO})_{6}$ partial pressure of $1 \times 10^{-5}$ Torr, while the data $(\boldsymbol{\Delta})$ were taken from the film fabricated in an $\mathrm{O}_{2}$ pressure of $1 \times 10^{-6}$ Torr relative to the $\mathrm{Cr}(\mathrm{CO})_{6}$ partial pressure of $1 \times 10^{-5}$ Torr. AES of the photolytic oxidative chemical vapor deposition of $\mathrm{Cr}_{2} \mathrm{O}_{3}$ and $\mathrm{CrO}_{2}$ (for high and low $\mathrm{O}_{2}$ partial pressure, respectively) are shown as insets (a) and (b), respectively.

ger electron spectroscopy (AES), as shown in the insets, Fig. 3(a) presents the Auger spectrum characteristic to a $\mathrm{Cr}_{2} \mathrm{O}_{3}$ rich sample, and Fig. 3(b) is representation for a $\mathrm{CrO}_{2}$ rich sample. The spectra show clearly that the $\mathrm{Cr}$ signal increases relative to the overlapping oxygen signal for the $\mathrm{Cr}_{2} \mathrm{O}_{3}$ samples as compared to the $\mathrm{CrO}_{2}$ samples.

In summary, we have used laser-initiated chemical vapor deposition and oxidation of $\mathrm{Cr}(\mathrm{CO})_{6}$ to make chromium oxide thin films. Like the photolysis of chomyl chloride $\left(\mathrm{CrO}_{2} \mathrm{Cl}_{2}\right),{ }^{14,30}$ the advantage of this technique is selective area deposition and strong texture growth in the films. Phase control of this system, at the surface or boundary layers, appears to be far more likely than the potential half metallic systems $\mathrm{La}_{0.65} \mathrm{Sr}_{0.35} \mathrm{MnO}_{3}$ (Ref. 31) and $\mathrm{NiMnSb}$ (Ref. 32) where surface segregation readily occurs. The MCD results provide indications of magnetic ordering in the unoccupied $t_{2 g}$ and $e_{g}$ bands of $\mathrm{L}_{2}$ and $\mathrm{L}_{3}$ chromium edges while the magnetization measurements show that the relative weight of both $\mathrm{Cr}_{2} \mathrm{O}_{3}$ and $\mathrm{CrO}_{2}$ phases depends on and can be controlled by the oxygen partial pressure. The $T_{C}$ of the film increases and approaches the bulk $T_{C}$ of $\mathrm{CrO}_{2}(397 \mathrm{~K})$ as we increase the partial oxygen pressure.

This work was supported by NSF through Grant No. DMR-98-02126, the Center for Materials Research and Analysis (CMRA) and the Nebraska Research Initiative at the University of Nebraska.

${ }^{1}$ H. van Lueken and R. A. de Groot, Phys. Rev. B 51, 7176 (1995).

${ }^{2}$ A. M. Bratkovsky, Phys. Rev. B 56, 2344 (1997).

${ }^{3}$ S. S. Manoharan, D. Elefant, G. Reiss, and J. B. Goodenough, Appl. Phys. Lett. 72, 984 (1998); X. W. Li, A. Gupta, T. R. McGuire, P. R. Duncombe, and Gang Xiao, J. Appl. Phys. 85, 5585 (1999); K. Suzuki and P. M. Tedrow, Phys. Rev. B 58, 11597 (1998).

${ }^{4}$ J. D. M. Coey, A. E. Berkowitz, L. L. Balcells, F. F. Putris, and A. Barry, Phys. Rev. Lett. 80, 3815 (1998).

${ }^{5}$ J. S. Kouvel and D. S. Rodbell, J. Appl. Phys. 38, 979 (1967).

${ }^{6}$ K. Schwarz, J. Phys. F: Met. Phys. 16, L211 (1986).

${ }^{7}$ S. Matar, G. Demazeau, J. Sticht, V. Eyert, and J. Kübler, J. Phys. I 2, 315 (1992).

${ }^{8}$ M. A. Korotin, V. I. Anisimov, D. I. Khomskii, and G. A. Sawatzky, Phys. Rev. Lett. 80, 4305 (1998).

${ }^{9}$ S. P. Lewis, P. B. Allen, and T. Sasaki, Phys. Rev. B 55, 10253 (1997).
${ }^{10}$ E. Kulatov and I. I. Mazin, J. Phys.: Condens. Matter 2, 343 (1990).

${ }^{11}$ K. P. Kämper, W. Schmitt, G. Güntherodt, R. J. Gambino, and R. Ruf, Phys. Rev. Lett. 59, 2788 (1987).

${ }^{12}$ R. Weisendanger, H.-J. Güntherodt, G. Güntherodt, R. J. Gambino, and R. Ruf, Phys. Rev. Lett. 65, 247 (1990).

${ }^{13}$ R. J. Soulen, J. M. Byers, B. Nadgormy, T. Ambrose, S. F. Cheng, P. R. Broussard, C. T. Tanaka, J. Nowak, J. S. Moodera, A. Barry, and J. M. D. Coey, Science 282, 85 (1998); R. J. Soulen, M. S. Osofsky, B. Nadgomy, T. Ambrose, P. Broussard, and S. F. Cheng, J. Appl. Phys. 85, 4589 (1999)

${ }^{14}$ W. J. DeSisto, P. R. Broussard, T. F. Ambrose, B. E. Nadgomy, and M. S. Osofsky, Appl. Phys. Lett. 76, 3789 (2000).

${ }^{15}$ E. E. Fullerton, K. T. Riggs, C. H. Sowers, S. D. Bader, and A. Berger, Phys. Rev. Lett. 75, 330 (1995).

${ }^{16}$ S. Adenwalla, G. P. Felcher, E. E. Fullerton, and S. D. Bader, Phys. Rev. B 53, 2474 (1996).

${ }^{17}$ W. H. Meiklenjohn and C. P. Bean, Phys. Rev. 102, 1413 (1956); A. P. Malozemoff, Phys. Rev. B 37, 7673 (1988); A. P. Malozemoff, Phys. Rev. B 35, 3679 (1985); N. C. Koon, Phys. Rev. Lett. 78, 4865 (1997).

${ }^{18}$ G. Ju, L. Chen, A. V. Nurmikko, R. F. C. Farrow, R. F. Marks, M. J. Carey, and B. A. Gurney, Phys. Rev. B 62, 1171 (2000).

${ }^{19}$ E. E. Fullerton, J. S. Jiang, M. Grimsditch, C. H. Sowers, and S. D. Bader, Phys. Rev. B 58, 12193 (1998).

${ }^{20}$ J. S. Jiang, G. P. Felcher, A. Inomata, R. Goyette, C. S. Nelson, and S. D. Bader, J. Vac. Sci. Technol. A 18, 1264 (2000).

${ }^{21}$ P. A. Dowben, Y.-G. Kim, S. Baral-Tosh, G. O. Ramseyer, C. Hwang, and M. Onellion, J. Appl. Phys. 67, 5658 (1990).

${ }^{22}$ K. Perkins, C. Hwang, M. Onellion, Y.-G. Kim, and P. A. Dowben, Thin Solid Films 198, 317 (1991).

${ }^{23}$ D. C. Mancini, S. Varma, J. K. Simons, R. A. Rosenberg, and P. A. Dowben, J. Vac. Sci. Technol. B 8, 1804 (1990).

${ }^{24}$ D. Welipitiya, C. N. Borca, P. A. Dowben, I. Gobulukoglu, H. Jiang, B. W. Roberson, and J. Zhang, Mater. Res. Soc. Symp. Proc. 475, 257 (1997).

${ }^{25}$ C. N. Borca, D. Welipitiya, S. Adenwalla, and P. A. Dowben, Phys. LowDimens. Semicond. Struct. 11, 173 (1997).

${ }^{26}$ C. B. Stagarescu, X. Su, D. E. Eastman, K. N. Altmann, F. J. Himpsel, and A. Gupta, Phys. Rev. B 61, R9233 (2000).

${ }^{27}$ J. Nogues and I. K. Schuller, J. Magn. Magn. Mater. 192, 203 (1999).

${ }^{28}$ E. F. Kneller and R. Hawig, IEEE Trans. Magn. 27, 3588 (1991).

${ }^{29}$ Practical Surface Analysis: Auger and X-ray Photoelectron Spectroscopy, edited by D. Briggs and M. P. Seah (Wiley, New York, 1996), Vol. 1.

${ }^{30}$ C. Arnone, M. Rothschild, J. G. Balck, and D. J. Erlich, Appl. Phys. Lett. 48, 1018 (1986).

${ }^{31}$ H. Dulli, E. W. Plummer, P. A. Dowben, J. Choi, and S.-H. Liou, Appl. Phys. Lett. 77, 88 (2000).

${ }^{32}$ D. Ristoiu, J. P. Nozieres, C. N. Borca, B. Borca, and P. A. Dowben, Appl. Phys. Lett. 76, 2349 (2000). 